\title{
Integration of an extended, immersive, gamified pharmacy simulation as a capstone event
}

\author{
Denise L Hope ${ }^{1}\left(\mathbb{D}\right.$, Gary D Grant ${ }^{1}\left(\mathbb{D}\right.$, Gary D Rogers ${ }^{2}\left(\mathbb{D}\right.$, Michelle A King ${ }^{1}(\mathbb{D})$ \\ 1 School of Pharmacy and Medical Sciences, Griffith University, Gold Coast QLD, Australia \\ 2 School of Medicine, Deakin University, Geelong VIC, Australia
}

\author{
Keywords \\ Capstone \\ Competence \\ Gamification \\ Pharmacy education \\ Simulation

\section{Correspondence} \\ Denise L Hope \\ Clinical Sciences 2, \\ G16_3.26 \\ Gold Coast Campus \\ Griffith University \\ Qld 4222 Australia \\ d.hope@griffith.edu.au
}

\begin{abstract}
Introduction: A gamified simulation was integrated as a capstone event for a new Australian undergraduate pharmacy programme. It aimed to consolidate previous learning and deliver an authentic activity aligned with self-determination theory to develop students' professional identity and enhance their competence, confidence, and collaborative skills. Description: A fullenvironment immersive simulation was constructed in which teams of final-year pharmacy students competitively managed their own virtual pharmacies over an extended period. Gamification of the simulation aimed to enhance student motivation and engagement while recognising the consequences of clinical and professional decision-making. Evaluation: Four years of gamified simulation encouraged outstanding student attendance and engagement. The quantitative evaluation revealed high student satisfaction (mean 4.7 out of 5) of the host courses, while the qualitative evaluation revealed that intended outcomes were met through the delivery of authentic, consolidated learning and enhancement of student confidence and professional identity. Conclusion: An extended, gamified simulation may provide a transformative learning event.
\end{abstract}

\section{Introduction}

Pharmacy graduates must be prepared for a rapidly evolving professional environment. It is incumbent upon pharmacy educators to equip them with the knowledge, skills, and attitudes required for their future practice. A new Australian undergraduate Bachelor of Pharmacy (BPharm) degree programme was developed in accordance with Accreditation Standards for Pharmacy Programs in Australia and New Zealand and Performance Outcomes Framework (Australian Pharmacy Council Ltd, 2020). The curriculum was mapped to the National Competency Standards Framework for Pharmacists in Australia (Pharmaceutical Society of Australia, 2016). Based on a spiral curriculum (Harden, 1999), an extended, immersive, gamified simulation was planned as a capstone team-based event. Capstone activities provide a culminating student experience to synthesise and integrate previous learning (Hirsch \& Parihar, 2014; Phillips et al., 2019).
This research paper details the development and preliminary evaluation of the capstone component of the new BPharm programme, namely the gamified simulation. The detailed description aims to inform pharmacy academics about the underlying pedagogy and practical implementation of the activity, including aspects such as world-building, gameplay, infrastructure, assessment, and marking rubrics. Institutional ethical approval was obtained from the Griffith University Human Research Ethics Committee (2016/594).

\section{Rationale}

The rationale for incorporating an extended, immersive, gamified simulation into the new undergraduate curriculum was multi-factorial. Firstly, reflection on the previous pharmacy programme and feedback from the pharmacy profession identified outcomes that had the potential to be enhanced. These equated to Domains 1 and 3 of the National Competency Standards Framework for Pharmacists in 
Australia (2016), namely Professionalism and ethics and Medicines management and patient care. Domain 1 addresses the legal, ethical, and professional responsibilities of pharmacists. While medicines legislation and ethical constructs can be taught in traditional contexts, professional practice behaviours and values and the application of ethical reasoning are more challenging to embed in curricula. Professional pharmacist identity is developed through authentic learning experiences (Mylrea, Sen Gupta, \& Glass, 2017), and professionalism and professional identity align with the affective learning domain, as identified by Bloom and colleagues in 1956 and Krathwohl and colleagues in 1964. Domain 3 of the Competency Standards, involving medicines management and patient care, addresses standards of patient-centred care, cultural responsiveness, and health promotion. Using a backward design approach (Wiggins \& McTighe, 2005), the pharmacists' Professional Practice Standards (Pharmaceutical Society of Australia, 2017) were explored to identify expected skills and attitudes of registered pharmacists for particular areas of practice that could inform curricular development for undergraduate education. For example, Standard 7 of the Professional Practice Standards focuses on health promotion and education, an area identified as needing improvement in the undergraduate outcomes.

Secondly, an additional issue was identified with the previous delivery of pharmacy practice and therapeutics courses, namely the isolated nature of cases and lack of interconnectivity, complexity, realworld application, and authenticity of the problembased learning approach utilised in independent workshops and simulations. The idea of developing an extended, immersive, gamified simulation emerged from the literature on active learning (e.g., Gleason et al., 2011; Aburahma \& Mohamed, 2015), gamification (e.g., Akl et al., 2013; Cain \& Piascik, 2015), and simulation (e.g., Gaba, 2004; McGaghie, Issenberg, Petrusa, \& Scalese, 2010). Furthermore, exposure to the European GIMMICS game (Sillius \& Van Der Werf, 2005; Koster, Schalekamp, \& Meijerman, 2017; Fens, Dantuma-Wering, \& Taxis, 2020) provided a model upon which to base this simulation.

The gamified simulation was planned to address the issues of authentic learning and meet the new BPharm programme goals of preparing competent, confident graduates with strong professional values for the Australian health care practice context. The approach would also need to meet the pharmacy programme accreditation requirements of providing student opportunities "to engage in interprofessional learning and practice (in real and/or simulated environments)" (Australian Pharmacy Council Ltd, 2020).

\section{Simulation}

Simulation is a long-accepted technique used in health professional and pharmacy education (Gaba, 2004; Bradley, 2006; Marken et al., 2010; McGaghie et al., 2010). It provides students with a standardised experience that replicates actual patient care or health care team interaction in a safe, controlled environment without risk of patient harm (Okuda \& Quinones, 2008; Crea, 2011; Lin et al., 2011). Simulation may improve student teamwork (Beaubien \& Baker, 2004; Fernandez et al., 2007; Marken et al., 2010; Vyas et al., 2012) and communication ( Lok et al., 2006; Englund \& Sjöström, 2011; Hussainy, Styles, \& Duncan, 2012). Simulation has been demonstrated as an effective technique to teach interprofessional teams how to engage in difficult conversations with patients (Marken et al., 2010).

Unrealistic and minimally engaging simulations are unlikely to achieve optimal learning outcomes (Lin et al., 2011), whereas realistic, immersive, authentic, and engaging simulations are more likely to excite and motivate students and deliver more effective learning (Huang, Rauch, \& Liaw, 2010). Extended simulation practices have been reported in medical education (Rogers et al., 2014; Rogers, Mey, \& Chan, 2017) and in pharmacy education (Van Der Werf, Dekens-Konter, \& Brouwers, 2004; Koster et al., 2017; Fens et al., 2020; Fens et al., 2021). Immersive, participatory simulations and games can provide a collaborative learning experience (Barab \& Dede, 2007).

\section{Gamification}

Gamification can be defined as applying the mechanics of games to make learning more engaging (Apostol, Zaharescu, \& Alexe, 2013; Moncada \& Moncada, 2014) or applying game concepts such as challenges, rewards, and leader boards to educational materials and classes (Bajko et al., 2015). Gamification refers to an approach that engages the psychology of play to design motivational learning experiences (McDougall, 2017). Rather than creating games, the term suggests transferring some of the positive attributes of a game to something that is not a game (Kim, 2015).

In higher education, gamification is most common in health professional education, with the ability to provide authentic situated learning without risk of harm to patients (Cain \& Piascik, 2015; Chang et al., 2015). Advantages of gamified environments include challenges to students, immediate feedback and the ability to learn from mistakes, critical thinking, and validation of ideas, all of which are skills transferrable to real-world contexts (Whitton \& Hollins, 2008; Cain et al., 2014; Cain \& Piascik, 2015). Learning by simulation and games can enhance the acquisition of new skills and knowledge and support the development of 
professional attitudes and behaviours (Whelan, 2005; Sauvé et al., 2007; Lyons, 2012).

Structural elements of games include rules, goals and objectives, feedback, conflict, competition, challenge and opposition, interaction, and the representation of the story (Prensky, 2001; Schwabe \& Göth, 2005). Deeper concepts of gamification include engagement, autonomy, the story, and its meaning (Kapp, 2012). It is argued that specific mechanisms are required in educational games for optimal learning to occur, including immediate feedback, interaction, active participation by the learner, player control of their learning, repeated practice, challenge, motivation, dialogue between players, and teamwork (Barnett et al., 2005; Schwabe \& Göth, 2005; Shreve, 2005; Virvou, Katsionis, \& Manos, 2005; Sauvé et al., 2007; Barclay, Jeffres, \& Bhakta, 2011). These gaming mechanisms may allow for knowledge and meaning to be constructed from experiences, aligning with a socioconstructivist pedagogy (Sauvé et al., 2007). The intersection of simulation and gaming may provide a rich environment for learning and has been reported as a means of teaching in the affective domain (Schoenly, 1994).

\section{Theoretical approach}

The overarching philosophy utilised in the development of the simulation was self-determination.
Self-determination theory was first articulated by Deci and Ryan (2008) as a theory of human motivation, development, and wellness. The theory has been applied to educational contexts and differentiates types of motivation and suggests that controlled motivation relies on rewards or punishment and may lead to rote, short-lived learning, whereas intrinsic motivation is associated with improved performance, well-being, and deeper learning (Williams, Saizow, \& Ryan, 1999; Deci \& Ryan, 2008; Orsini, Evans, \& Jerez, 2015). Authors have suggested that the human needs of autonomy, competence, and relatedness are essential to achieve intrinsic motivation (see Figure 1) and that autonomy-supportive education in the health professions would benefit student outcomes and translate into improved patient health outcomes (Williams et al., 1999; Orsini et al., 2015). Reeve (2002, p. 183) suggested that "autonomously-motivated students thrive in educational settings" and that "students benefit when teachers support their autonomy". The objectives of the gamified simulation were to support student autonomy to create an environment in which student pharmacists occupied the role of the health professionals to experience the decision-making and responsibility and ultimately enhance their confidence and professional identity.

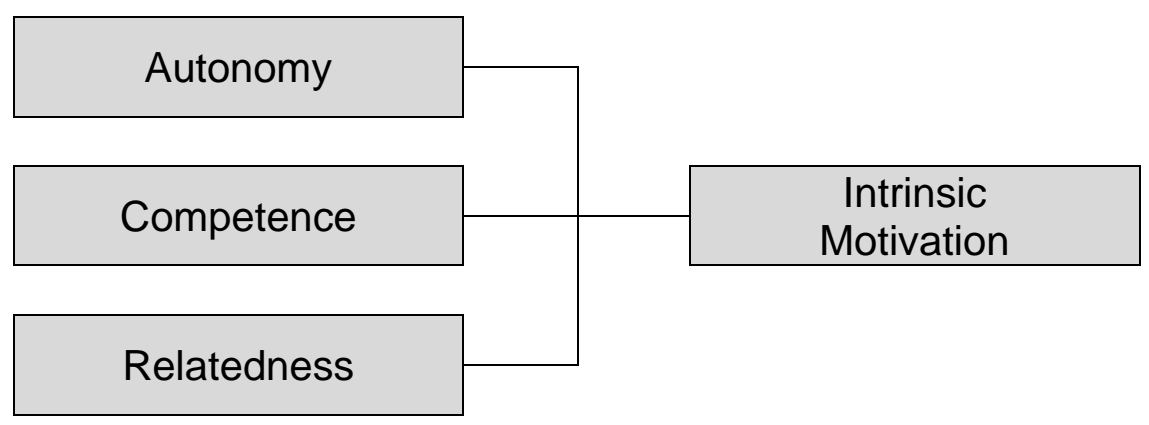

Figure 1: Self-Determination Theory suggests that the basic human needs of autonomy, competence, and relatedness influence intrinsic motivation (Deci \& Ryan, 2008)

An increasing focus on health professional competency (Bruno et al., 2010; Nash et al., 2015; Koster et al., 2017) underlines the critical need for authentic, practice-based learning and assessment opportunities (Croft et al., 2019). Koster and colleagues in 2017 described competence in pharmacy education as contextual, developmental, and multidimensional. They suggested that competence can only be demonstrated in pharmacy students when pertinent knowledge, skills, and attitudes are applied cohesively to a relevant context (Koster et al., 2017). Gamified simulation, otherwise known as serious gaming, has been suggested as a suitable form of assessment in competency-based education (Van Der Werf et al., 2004; Koster et al., 2017; Fens et al., 2020). Previous research has demonstrated the effectiveness of simulation in improving pharmacy student competence and confidence (Bajis et al., 2019). 


\section{Aim}

The overall aim of the gamified simulation was to provide a rich, authentic learning experience during which students developed confidence, competence, and professional identity, providing the final preparation for graduation and subsequent pharmacy internship.

\section{Learning outcomes}

Specific gamified simulation intended learning outcomes were:

- Evaluate advanced practice-based cases to apply legal, ethical, and clinical reasoning;

- Apply tailored communication skills required for all pharmacy practice related consultations to deliver person-centred care;

- Integrate knowledge for safe and appropriate delivery of primary and preventative healthcare;

- Evaluate complex practice-based cases to dispense medicines, including assessment of the legal, Pharmaceutical Benefits Scheme (PBS) [the national scheme for subsidising medicines] and clinical appropriateness of the prescribed medicines, applying a systematic dispensing procedure and counselling of patients/carers;

- Apply research evidence to deliver pharmaceutical health education and training; and

- Collaborate in teams to plan, manage and conduct simulated pharmacies to deliver holistic personcentred care.

\section{Description}

The activity was a full environment gamified simulation involving teams of final-year pharmacy students who staffed and competitively managed their own simulated pharmacies over an extended period. The capstone event utilised simulation and gamification, with a significant emphasis on the development of lifelong learning skills through an evidence-based approach. The first four annual iterations of the gamified simulation, from 2016, were conducted in person and face-to-face, utilising physical spaces on a University campus. The fifth iteration, in 2020, was conducted online as a consequence of the COVID-19 pandemic. The adjustments made to shift the entire simulation to the virtual space were many and profound and, as such, are beyond the scope of this paper. The description herein applies to the in-person simulation, as it was initially designed and intended.

\section{Design approach}

A backward design approach was employed in the planning stages in which the curriculum expectations and desired outcomes of the gamified simulation were first identified (Wiggins \& McTighe, 2005). Continuous assessment was embedded throughout and comprised many discrete tasks within the whole. The numerous components of the simulation were developed, scaffolded, and interconnected, including clinical cases, dispensing and counselling cases, recorded verbal counselling submissions, in-person consultations using trained simulated patients, as well as clinical and professional telephone calls.

The design of the simulation facilitated learning in the cognitive, psychomotor, and affective domains, as identified and hierarchically stratified by Bloom, Krathwohl, Anderson, and Harrow (2001; 1956; 1972; 1964). Learning in the cognitive domain was assessed through clinical case studies, dispensing cases, and associated medication-related problem management. Additionally, student teams were required to plan, prepare, and deliver a discrete research project by the close of the simulation. Learning in the psychomotor domain was primarily assessed through OSCEs. Learning in the affective domain was determined by analysing students' reflective journals using a validated assessment tool (Rogers et al., 2018).

The gamified simulation was adapted from the concept of the Groningen Institute Model for Management in Care Services (GIMMICS), developed at the Department of Pharmacy, University of Groningen, Netherlands (Van Der Werf et al., 2004; Schaafsma et al., 2010; Fens et al., 2020). Other universities have joined the GIMMICS consortium, applying the same model for pharmacy educational simulations (Boyd et al., 2017; Koster et al., 2017). A similar model has also been applied to other health professions, including physiotherapy and podiatry (Mardjan, 2016). Concepts from the Dutch that were utilised in the development of this Australian gamified simulation were the model of a competitive, extended, immersive pharmacy simulation, the game scoring platform, and the convention that one day in the simulation represented one week in professional practice (Fens et al., 2020). The latter allowed for the progressive improvement or worsening of simulated patients' health conditions and the development of adverse drug reactions from medicines previously supplied. The virtual city and backstory underpinning the simulation, the pharmacies, prescribers, patients, cases, plan, and infrastructure were developed by a team of academic pharmacists and practitioners in the School of Pharmacy and Medical Sciences, Griffith University, Australia. 


\section{World-building}

In any simulation, the story or background context is particularly important to the scenario to ensure the learning outcomes are achieved (de Freitas \& Oliver, 2006). When a simulation is immersive and extended over multiple days and weeks, world-building becomes increasingly important to contextualise and perpetuate the story within the simulation. World-building is the process of constructing an imaginary world for use in games or literature (Oxford Reference, 2019).

In developing a simulation to focus on pharmacyrelated functions and tasks, the world-building involved the creation of a fictional virtual city with numerous pharmacies. The imaginary city was endowed with unique geographic, socioeconomic, and healthcare demographics. The simulation was set in a rural, mining city with high unemployment, a male gender imbalance, and significant Indigenous and elderly populations. The city provided various healthcare services, including public and private hospitals, general practice clinics, nursing homes, a drug and alcohol service, an Indigenous health service, and a palliative care team. Students learned about the setting for the gamified simulation in advance of their participation, and the world-building details were published on the accompanying game website. During the simulation, the created world was ever-present, with all prescribers and patient locations, addresses, contact, and interactions perpetuating the built world story.

\section{Teams}

Final-year pharmacy students were the target participants for this capstone event. The simulation was team-based and relied on cooperative learning. This approach was underpinned by Social Independence Theory, which proposes that learning from peers has a powerful influence on students' cognitive development (Gleason et al., 2011; Johnson, Johnson, \& Smith, 2007). Cooperative learning is supported by the principles of positive interdependence, which include mutual encouragement, promotive interaction, and individual accountability. Such learning is supported by team reflection and social skills (Gleason et al., 2011). These principles were reinforced in the design of the simulation through the implementation of daily team staff meetings, intended to provide debrief and reflection at the close of each day's activities, and through overall peer evaluation that had the potential to scale students' individual marks up or down from the final team result.

Teams typically comprised between five and eight students and were purposefully constructed by academic staff. Teams were constructed to contain a mix of genders, international and domestic students, academic achievement, pharmacy experience, and to separate known social groups. For each iteration of the gamified simulation, between five and eight teams competitively participated. In 2016, a single cohort of undergraduate BPharm students participated, whereas, in 2017, part-time postgraduate students from a new Master of Pharmacy (MPharm) programme joined the simulation in separate teams, two days a week. From 2018, the teams were mixed, comprising full-time BPharm and part-time MPharm students, as this approach was considered to be more reflective of actual pharmacy practice. The mixed cohort teams were encouraged to practise handover skills with other members of their team who may not have been present for particular cases or activities. Additionally, in 2018, visiting students from a Malaysian university participated full-time for two of the three weeks of the simulation.

Teams were required to construct and submit a Norms Contract on the first day of the game, which equated to the first assessment task and publication of scores. The Norms Contract was designed for participants to articulate their personal aspirations for team outcome, record their expectations of the team as a whole, and summarise their teams' committed values. Such contracts have reportedly been utilised in other teambased simulation activities (Mottner, 2009). If an interpersonal conflict arose in any team, students were directed back to their Norms Contract first to review their agreed expectations and goals. Students were prepared in advance of the simulation, via a two-hour preparatory lecture, for all aspects of the activity, including the team Norms Contract, peer-scaling of marks, and gameplay.

\section{Gameplay}

Students assumed the role of pharmacists during the three-week simulation. Each day involved planned and scaffolded realistic clinical and pharmacy practicerelated scenarios utilising simulated patients. Daily tasks included prescription dispensing and patient counselling, clinical case preparation, in-person and recorded verbal medicine counselling, management of over-the-counter simulated patient consultations (including symptom-based requests, direct product requests, device demonstrations, information inquiries, telephone inquiries, and prescriber contact to resolve legal or clinical problems with prescriptions). The patient presentations, cases, and potential outcomes were many and varied, providing a multitude of learning opportunities for the student participants. A typical day averaged about three face-to-face cases with simulated patients (SPs), one complex clinical case to prepare a detailed plan for, and an array of other telephone calls and walk-in cases or activities, such as 
random tablet/capsule identification tasks, and approximately 25 prescription cases. Each prescription case required a full assessment of legality, compliance with Australian PBS requirements, safety and appropriateness for the patient, in addition to complete written patient counselling.

During the simulation, teams received regular communications, including news reports, weather reports, and other information that might prepare them for events to come. For example, flooding rain forecasts prepared them for a disaster day that arrived unexpectedly and delivered additional learning outcomes regarding disaster preparedness, which were unable to be delivered in more traditional teaching approaches. The communications often included health-related news stories to provide context to the built world of the simulation, such as reports of an influenza outbreak, which spontaneously encouraged teams to print and post public health messages regarding vaccination and inquire about immunisation during their simulated patient consultations. Healthrelated communications were also employed as a subtle way to provide feedback.

Each simulation day closed with a team staff meeting to allow for debrief, feedback and future planning. Staff continually monitored teams and individuals to provide any pastoral care that might have been required. During the simulation, academic and casual pharmacist staff were involved as managers, facilitators, assessors, simulated prescribers, and simulated patients.

\section{Simulated patients}

Simulated or standardised patients (SPs) are valuable in conducting simulations in health professional education (Marken et al., 2010; Ryall, Judd, \& Gordon, 2016; Kaplonyi et al., 2017; Butt, 2018; Bogossian et al., 2019). They have been widely used in pharmacy education (Chen, Kiersma, \& Abdelmageed, 2015; Smithson et al., 2015; Bowers et al., 2017; Kubota et al., 2018;) and also in research on pharmacist counselling practices (Paravattil, Kheir, \& Yousif, 2017). SPs help to lend authenticity to simulated learning and assessment activities, allowing students to practise their questioning and counselling techniques without concern of causing harm. If SPs are suitably trained in feedback techniques, they can also provide feedback to student participants, after the simulation, on their communication skills (Chen et al., 2015; Smithson et al., 2015; Kubota et al., 2018;).

The cases involving SPs were planned in advance, and actors were employed to role-play patients in the gamified simulation. They were provided detailed patient histories for each of their cases ahead of their participation. If simulated patients were required to act in multiple cases, they would complete one case for all teams, take a break, and then perform the second case, usually supported by a costume or appearance change. As SPs role-played the designated case for each team in turn, they were accompanied by a pharmacist academic who undertook the case assessment using paper-based (2016 and 2017) or iPad digital (2018 and 2019) marking rubrics.

\section{Assessment and scoring}

Assessment during the gamified simulation was continuous. As tasks and activities were completed, they were marked and scores posted to the simulation's website, where students could see team scores represented graphically and in tabular form. This aspect enhanced the competitive gameplay, regularly engaged the students in the tasks at hand, and provided timely and ongoing feedback. The scoring approach was rewards-based, with teams being allocated positive or possibly negative marks for every activity based on performance, including professionalism and clinical decision-making. The possibility of negative marking was considered a powerful feedback tool for students who might simulate illegal practice, such as dispensing a prescription that did not meet state legal requirements or making poor clinical choices that generated potential patient harm, such as dispensing a medicine for which the patient had a recorded allergy.

The example of the scoring approach was similar in concept to that of SimCity ${ }^{\mathrm{TM}}$, which is a popular computer-based city builder game, in which the user starts with a population and attempts to grow their population through building additional infrastructure and resources within the digital game (Electronic Arts Inc., 2020). In the gamified simulation pharmacy, teams started with a uniform population of ten thousand patients and would earn or lose patients based on the outcomes of their performance in their pharmacyrelated tasks. The team that finished with the most patients won the game (Van Der Werf et al., 2004; Fens et al., 2020). From overall team scores, peer-scaling was applied to derive individual student scores for the capstone event.

\section{Marking rubrics}

An important adaptation made in response to the gamification of the simulation was the alteration of all marking rubrics for assessments. Whereas traditional assessments are marked on a positive scale, e.g. from 0 to 100 , to adopt gaming elements, all marking rubrics had to reflect the potential loss of marks for poor performance. Therefore, rubrics were amended to range from -100 to 100 , for example, in which a 0 
indicated mediocre outcomes where patients were neither gained nor lost. The consequences of negative scoring on students and teams were quite profound, resulting in illegal, unethical, or unprofessional simulated behaviour that might have led to poor patient outcomes, translated into negative scoring and loss of forward momentum in the competition. The intention of the academic staff was for negative scores to provide relevant feedback on performance and a prompt for team members to reflect on their actions and discuss future improvements and remediation.

Marking rubrics were entirely revised for use in the gamified simulation. For example, written dispensing and counselling assessments are traditionally marked in detail, with very strict rubrics and cumulative marks being earned for each section of the dispensing template. In contrast, the rubric for marking dispensing in the gamified simulation required transformation to the negative and positive scale, plus streamlining to allow for more holistic marking within the given time constraints of the simulation, even though students used the same dispensing template. The 7-point simulation rubric relied on the professional judgement of experienced pharmacist practitioners to make overall decisions on team performance when marking. Table I details the totalled marking of traditional dispensing and the holistic marking of the gamified simulation marking.

Table I: Traditional versus Gamified marking for dispensing and counselling

\begin{tabular}{lclc}
\hline $\begin{array}{l}\text { Traditional } \\
\text { Detailed marking }\end{array}$ & Marks & $\begin{array}{l}\text { Gamified simulation } \\
\text { Holistic marking }\end{array}$ & Marks \\
\hline Assessment of legality & 10 & Illegal action/patient harm \\
Assessment of PBS compliance & 10 & PBS error or treatment not optimised \\
Patient/caregiver questions & 10 & Borderline & -100 \\
Medicine dose references & 3 & Adequate & 0 \\
Medication-related problem resolution & 10 & Good \\
Dispensed label & 20 & Very good \\
Counselling and referral & 37 & Excellent \\
\hline Summed total & $\mathbf{1 0 0}$ & \\
\hline
\end{tabular}

Traditional OSCE marking is often validated and weighted according to the particular case (Austin et al., 2003). The OSCE marking rubrics in the gamified simulation were similar to the dispensing rubrics, with two negative to positive scales marked and summed for an overall score from -200 to 200 patients. This facilitated the application of professional judgement in the overall marking of OSCEs within the time constraints of the simulation, given that the assessor was usually shadowing an SP who role-played the case for each team in turn. The pharmacist marking provided a score from -100 to 100 patients for focused communication skills and an additional -100 to 100 patients for general performance (based on appropriate clinical and/or professional outcomes for the patient) (see Table II).

Verbal counselling was traditionally marked using a rubric of sub-components, totalling 20 marks. The same rubric was employed for both in-person and recorded verbal counselling in the gamified simulation, and then a formula was applied to convert the score out of 20 to one on the scale from -200 to 200 patients. The calculated score $(x)$ was achieved by subtracting 10 from the raw score out of $20(y)$ and the result multiplied by 20 , i.e. $x=(y-10) * 20$.

Table III summarises a range of calculated scores.
Table II: Gamified marking for OSCEs

\begin{tabular}{lr}
\hline Holistic marking & Marks \\
\hline Illegal action/patient harm & -100 \\
Inadequate & -75 \\
Treatment not optimised & -50 \\
Lack of clarity & -25 \\
Borderline & 0 \\
Adequate & 25 \\
Good & 50 \\
Very good & 75 \\
Excellent & 100 \\
\hline
\end{tabular}

Table III: Gamified calculated scores for verbal counselling

\begin{tabular}{cc}
\hline Raw score (out of 20) & Calculated score (out of 200) \\
\hline 0 & -200 \\
2.5 & -150 \\
5 & -100 \\
10 & 0 \\
12.5 & 50 \\
15 & 100 \\
17.5 & 150 \\
20 & 200 \\
\hline
\end{tabular}




\section{Feedback}

The most uncomfortable adaptation for students in such an extended simulation was the modified nature of feedback. Feedback was more subtle than providing the correctly drafted answer. Teams were encouraged to rely on real-world feedback mechanisms, i.e., selfreflection, reflection and feedback from team members, colleagues, and simulated patients. The most impactful form of feedback was the scoring itself. As scoring was continuous and progressive, students constantly monitored the game site to see how they or their team performed in particular cases. This provided very timely feedback. If students claimed they did not understand where they went wrong in specific cases, they were encouraged to debrief with a team that performed well in that case. If a team did something that was judged as potentially dangerous, illegal or there was suspicion on behalf of the supervising academics that indirect feedback would not achieve the desired remediation, then more direct feedback was provided.

\section{Infrastructure}

An essential element in the development of an immersive face-to-face gamified simulation is the infrastructure: having a suitable venue to create the requisite number of simulated pharmacies and the technological capabilities, such as internet, telephone, and physical resources, to support the simulation. Schools of Pharmacy with existing problem-based learning $(\mathrm{PBL})$ or clinical skills rooms may have the advantage of having suitable, applicable infrastructure. The simulation developed in this study used small clinical skills rooms in the School of Medicine for the first two years. From the third year, a large, open facility within the university was employed, and custom construction of pharmacy spaces was undertaken, using prefabricated wall panelling. The rooms were then equipped with desks, chairs, computers, printers, barcode scanners, iPads, a counselling counter, and physical references and resources essential for contemporary Australian pharmacy practice.

\section{Timetabling}

The gamified simulation was conducted full-time for a three-week period, during which team pharmacies were expected to be open and functioning from 8:00 am until 4:00 pm Mondays to Fridays. The extended period of the simulation allowed for evolving patient medical conditions and complexity of practice. It was necessary to secure uninterrupted time in students' timetables to enable their full-time participation in the simulation. This matter was addressed during the curriculum development of the new Bachelor of Pharmacy programme. The opportunity was available to plan and timetable no other active teaching commitments during the simulation to allow students' full-time attendance. The simulation was then a major component of two parallel courses (Pharmacy Practice IV and Pharmacotherapeutics IV) and situated in weeks eight through ten of the final 12 -week term to provide an actual capstone experience. The two weeks of traditional classes following the simulation allowed for student debrief, feedback, and discussion on the learning and outcomes of the simulation.

\section{Evaluation}

The annual gamified simulation was first conducted in 2016. Across the first four face-to-face offerings of the simulation, 180 students participated, comprising 136 undergraduate, 38 postgraduate, and six visiting international students. As the gamified simulation was a critical capstone activity of the new BPharm programme, an array of lenses of evidence was sought to evaluate its impact and outcomes (Brookfield, 1995). Lenses included critical self-reflection, student and graduate data, internal and external peer observation and feedback, the pharmacy profession, and the national and international scholarly audience. Student, graduate, and peer feedback are summarised herein.

\section{Student feedback}

While student participation in the gamified simulation was not compulsory, the successive iterations of the gamified simulation attracted nearly $100 \%$ attendance each year. Engagement with the simulation appeared to result from the gamified aspects as students were motivated to succeed, not wanting to let their team members down or be subsequently punished by peer scaling. Simulation participation was overwhelmingly viewed positively, as evidenced by quantitative student experience survey results (Table IV) and qualitative feedback.

Student Experience of Course (SEC) evaluations were conducted centrally by the university each semester for all courses. The quantitative evaluation was derived from the question "Overall I am satisfied with the quality of this course", for which students rated their agreement on a 5-point Likert scale (where 1=strongly disagree and $5=$ strongly agree), as summarised in Table IV.

Table IV: Student evaluation of course(s) hosting the gamified simulation (out of 5)

\begin{tabular}{lcccc}
\hline & $\mathbf{2 0 1 6}$ & $\mathbf{2 0 1 7}$ & $\mathbf{2 0 1 8}$ & $\mathbf{2 0 1 9}$ \\
\hline Pharmacy Practice Course & 4.7 & 4.4 & 4.9 & 4.9 \\
Pharmacotherapeutics Course & 4.5 & 4.6 & 4.6 & 4.7 \\
\hline
\end{tabular}


SEC evaluations invited free-text comments from students for the question: "What did you find particularly good about this course?" All comments that related to the gamified simulation were extracted and subjected to inductive thematic analysis (Braun \& Clarke, 2006). Textual student quotes were iteratively read and reread by two authors until themes emerged. An inductive approach allowed for the emergence of findings from the frequent, dominant, or significant themes in the raw textual data. The inductive approach is commonly used in evaluation research (Thomas, 2006).

Five dominant themes were detected in student feedback: (1) emotional response to the simulation; (2) authenticity of learning; (3) extending learning; (4) consolidating learning; and (5) future practice. Students from each year from 2016 to 2019 were coded A through $D$ to correspond with the year level of their participation (where $2016=\mathrm{A}$ ); the participant number equated to the anonymised number from the student evaluation.

\section{(1) Emotional response to the simulation}

The emotional experiences reflected upon from inside the simulation often related to teamwork, collaboration and working with others, as exemplified in the following:

"The game was a really great and interactive learning experience; it helped me to work in a team within a stressful environment." $(A 16,2016)$

While many students reported the activity as intense or stressful, most recognised the value of the experience as well, as highlighted by the following students:

"The [simulation] game was an intense but awesome experience." (A8, 2016)

"[The simulation] was the most stressful yet rewarding three weeks of my life." $(A 17,2016)$

"I've learnt so much about myself in terms of dealing with difficult situations I am faced [with] in a pharmacy setting." (D16, 2019)

\section{(2) Authenticity of Learning}

The authentic approach to the simulation allowed students to practise in as close to a real-world situation that could feasibly be created outside of the workplace. Feedback regarding the real-world connection included:

"Enjoyed the game. Got to practice real-life skills." (A10, 2016)
"Active learning opportunities that are relevant to future work and learning. The game was an amazing opportunity for developing skills in collaboration and real-world application." (D7, 2019)

A valuable aspect of the authentic experience for students was being able to practise holistic, patientcentred care, as exemplified by:

"It was really interesting to be able to put into practice the ability to see a patient holistically... I enjoyed the experience of having the full pharmacist responsibility in a safe space." $(A 8,2016)$

"The game made me understand what the [term] holistic care really means." (A11, 2016)

\section{(3) Extending Learning}

Students reported that the activity enhanced their knowledge and extended their current scope, such as:

"I have gained a lot of knowledge from my peers." (B9, 2017)

"I found that [the simulation] was a very valuable experience and made me expand my knowledge on medications greatly." (D3, 2019)

"I was able to experience more broad situations that those I currently experience at work." (A8, 2016)

Additionally, students described how the simulation helped to extend their practical skills:

"The [simulation] game was very engaging and has resulted in a massive improvement in my medications counselling and patient-centred care." (A15, 2016)

\section{(4) Consolidating Learning}

The capstone nature of an activity such as the gamified simulation is intended to revisit and consolidate prior learning. The capstone approach of the activity was discussed by the following students:

"Allowed everyone to revisit aspects of our degree and begin to get a feel for what our roles and responsibilities will be as pharmacists." (B14, 2017)

"The game was a good way to conclude the degree and bring everything together." $(C 8,2018)$

"Preparing us for real-world practice... Excellent capstone course." (C16, 2018) 
The consolidation of learning was exemplified by:

"This helped me to thoroughly consolidate my knowledge and prepare for internship." (A14, 2016)

Preparation for internship and future practice were also identified in the theme future practice.

\section{(5) Future Practice}

The overall aim of the gamified simulation was to improve student confidence and competence prior to internship. Success of these aims being met was demonstrated by the following feedback focused on students' future roles:

"Very helpful in learning to apply knowledge in reallife situations. It has enhanced my confidence as a future health professional." (B6, 2017)

"The [simulation] game was fantastic in helping us put our learning into practice and preparing us for practice as pharmacists." (B15, 2017)

"The [simulation] was particularly good at keeping everyone engaged and getting us ready for the duties of a pharmacist." (D10, 2019)

\section{Graduate feedback}

Graduates of the BPharm programme that hosted the gamified simulation have appraised the programme very highly. They rated skills development, teaching quality, learning resources, and overall quality of educational experience above national averages in the Australian Quality Indicators for Learning and Teaching 2017-2019 Student Experience Survey (Social Research Centre Pty Ltd \& Commonwealth of Australia, 2020).

Additionally, unsolicited e-mail feedback was received from several graduates who had reflected on the transformative experience of the gamified simulation during their respective internships. One graduate related an incident that had occurred in the simulation that resonated with them and continued to influence their intern practice:

"The Game was such an integral part of my learning and has impacted me so much more than I thought it would. For example, there was an interaction in the game where I contacted the [simulated doctor]... and was most certainly not adequately prepared for the phone conversation... [case details] and as a result, the doctor hung up on me, a second interaction with that same doctor regarding the same patient where I wasn't able to quickly recommend an alternative treatment saw the doctor hang up on me again. This interaction significantly impacted my practice during my current internship year; I now have a mental checklist of all information that is required or that even may be required in case a health professional is in need of any further clarification." (e-mail to staff, 4 April 2018)

Another graduate reflected on the interprofessional nature of the simulation and their own maturation:

"...thank you for the experiences we were provided through The Game to learn to interact with each other, with other health professionals and patients and to grow and mature through those experiences." (e-mail to staff, 5 March 2018)

\section{Peer and professional feedback}

Survey feedback solicited from pharmacy intern training providers was very positive regarding the preparedness of BPharm graduates. Academic scholars and peer professional pharmacists both observed and participated in the simulation, also providing positive feedback. A professional colleague, pharmacy owner and executive member of a peak professional pharmacy organisation, wrote:

"I was impressed to see the level of detail and realism in the Community Pharmacy settings that the students were able to partake in, and also the real-life problem-solving skills they will be able to develop. As a pharmacy proprietor, I recognise the value that Students and Interns add through working in a pharmacy and their provision of vital services, and I believe the [simulation] games will significantly assist in their preparedness and capability." (e-mail to staff, 13 December 2016)

Both academic courses that hosted the gamified simulation (Pharmacy Practice IV and Pharmacotherapeutics IV) underwent external benchmarking (in 2018) and external curriculum review (in 2019). The assessments involved in the gamified simulation were described by assessors as "appropriate to achieve the aim of assessing professional competence" and "clear, well-designed, and robust".

\section{Related research and future plans}

Iterative offerings of the gamified simulation have been improved and enhanced through the design-based approach (T. Anderson, 2005; T. Anderson \& Shattuck, 2012). While academic staff self-reflection, traditional student evaluation of the activity, and feedback from graduates and peers have been positive, further evaluation of the gamified simulation approach could be undertaken. Additional qualitative research was 
undertaken to explore student learning and the student experience in this emotionally intensive capstone activity, which identified major themes of teamwork, patient-centeredness, medicines provision, future practice, and the learning experience (Hope et al., 2021). The primary author of this paper is undertaking quasi-experimental dissertation research to compare student participants' pre- and post-self-assessment of professional pharmacist competencies (Pharmaceutical Society of Australia, 2016) with other final-year pharmacy students who did not undertake the initiative. The assessment of students' affective learning over the course of the gamification simulation is also being investigated. As student stress has a potential impact on learning, it would be useful to compare the perceived and actual physiological stress of participants in an extended gamified simulation to the stress experienced in more traditional teaching approaches.

\section{Conclusion}

An extended, immersive, gamified pharmacy simulation embedded into the curriculum as a capstone event has delivered on intended learning outcomes of enhancing student competence, confidence, professional identity and preparedness for practice. This approach may provide a transformative learning experience to final-year pharmacy students.

\section{References}

Aburahma, M. H., \& Mohamed, H. M. (2015). Educational games as a teaching tool in pharmacy curriculum. American Journal of Pharmaceutical Education, 79(4), Article 59. https://doi.org/10.5688/ajpe79459

Akl, E. A., Kairouz, V. F., Sackett, K. M., Erdley, W. S., Mustafa, R. A., Fiander, M., Gabriel, C., \& Schünemann, H. (2013). Educational games for health professionals. Cochrane Database of Systematic Reviews (3), 1-47. https://doi.org/10.1002/14651858.CD006411.pub4

Anderson, L. W., Krathwohl, D. R., \& Bloom, B. S. (2001). A taxonomy for learning, teaching, and assessing: a revision of Bloom's taxonomy of educational objectives: Longman

Anderson, T. (2005). Design-based research and its application to a call centre innovation in distance education. Canadian Journal of Learning and Technology/La revue canadienne de l'apprentissage et de la technologie, 31(2)

Anderson, T., \& Shattuck, J. (2012). Design-based research: A decade of progress in education research? Educational Researcher, 41(1), 16-25

Apostol, S., Zaharescu, L., \& Alexe, I. (2013). Gamification of Learning and Educational Games. Paper presented at the
The International Scientific Conference eLearning and Software for Education

Austin, Z., O'Byrne, C., Pugsley, J., \& Munoz, L. Q. (2003). Development and validation processes for an objective structured clinical examination (OSCE) for entry-to-practice certification in pharmacy: the Canadian experience. American Journal of Pharmaceutical Education, 67(3), 76

Australian Pharmacy Council Ltd. (2020). Accreditation Standards, Performance Outcomes Framework and Supporting Documents. Available at:

https://www.pharmacycouncil.org.au/resources/pharmacyprogram-standards/

Bajis, D., Chaar, B., Basheti, I. A., \& Moles, R. (2019). Pharmacy students' medication history taking competency: Simulation and feedback learning intervention. Currents in Pharmacy Teaching and Learning, 11(10), 1002-1015

Bajko, R., Hodson, J., Seaborn, K., Livingstone, P., \& Fels, D. (2015). Guilds, Die Rolls, and Leaderboards: Gamification of Two Undergraduate Multimedia and Social Media Courses. Paper presented at the Proceedings of the EDSIG Conference

Barab, S., \& Dede, C. (2007). Games and immersive participatory simulations for science education: an emerging type of curricula. Journal of Science Education and Technology, 16(1), 1-3

Barclay, S. M., Jeffres, M. N., \& Bhakta, R. (2011). Educational card games to teach pharmacotherapeutics in an advanced pharmacy practice experience. American Journal of Pharmaceutical Education, 75(2)

Barnett, D. J., Everly, G. S., Parker, C. L., \& Links, J. M. (2005). Applying educational gaming to public health workforce emergency preparedness. American Journal of Preventive Medicine, 28(4), 390-395

Beaubien, J., \& Baker, D. (2004). The use of simulation for training teamwork skills in health care: how low can you go? Quality and Safety in Health Care, 13(suppl 1), i51-i56

Bloom, B. S., Engelhart, M. D., Furst, E. J., Hill, W. H., \& Krathwohl, D. R. (1956). Taxonomy of Educational Objectives, Handbook I: The cognitive domain (Vol. 19): New York: David McKay Co Inc

Bogossian, F. E., Cant, R. P., Ballard, E. L., Cooper, S. J., Levett-Jones, T. L., McKenna, L. G., Ng, L. C., \& Seaton, P. C. (2019). Locating 'gold standard'evidence for simulation as a substitute for clinical practice in pre-licensure health professional education: A systematic review. Journal of Clinical Nursing

Bowers, R., Tunney, R., Kelly, K., Mills, B., Trotta, K., Wheeless, C. N., \& Drew, R. (2017). Impact of standardized simulated patients on first-year pharmacy students' knowledge retention of insulin injection technique and counseling skills. American Journal of Pharmaceutical Education, 81(6), 113. https://doi.org/10.5688/ajpe816113

Boyd, M., Solanki, V., Anderson, C., Sonnex, K., \& Brydges, S. (2017). Pharmacy Leadership and Management: A new high fidelity simulation to prepare students for their future practise. Paper presented at the Monash Pharmacy Education Symposium, Prato, Italy 
Bradley, P. (2006). The history of simulation in medical education and possible future directions. Medical Education, 40(3), 254-262

Braun, V., \& Clarke, V. (2006). Using thematic analysis in psychology. Qualitative Research in Psychology, 3(2), 77-101

Brookfield, S. (1995). The getting of wisdom: What critically reflective teaching is and why it's important. In Becoming a Critically Reflective Teacher (pp. 1-28)

Bruno, A., Bates, I., Brock, T., \& Anderson, C. (2010). Towards a global competency framework. American Journal of Pharmaceutical Education, 74(3). doi:10.5688/aj740356 Butt, M. F. (2018). Simulated patients uncovered. The Clinical Teacher, 15(1), 81-82

Cain, J., Conway, J. M., DiVall, M. V., Erstad, B. L., Lockman, P. R., Ressler, J. C., Schwartz, A. H., Stolte, S., \& Nemire, R. E. (2014). Report of the 2013-2014 academic affairs committee. American Journal of Pharmaceutical Education, 78(10)

Cain, J., \& Piascik, P. (2015). Are Serious Games a Good Strategy for Pharmacy Education? American Journal of Pharmaceutical Education, 79(4), 47. https://doi.org/10.5688/ajpe79447

Chang, Y. H., Poh, H. D. Y., Wong, L. L., Yap, G. J. Y., \& Yap, Y.-L. K. (2015). Student Preferences on Gaming Aspects for a Serious Game in Pharmacy Practice Education: A CrossSectional Study. JMIR Medical Education, 1(1), e2. https://doi.org/10.2196/mededu.3754

Chen, Y.-C., Kiersma, M. E., \& Abdelmageed, A. (2015). Evaluation of student perceptions of standardized patient simulation on patient counseling confidence during introductory pharmacy practice experiences. Currents in Pharmacy Teaching and Learning, 7(6), 811-818. https://doi.org/10.1016/j.cptl.2015.08.008

Crea, K. A. (2011). Practice Skill Development Through the Use of Human Patient Simulation. American Journal of Pharmaceutical Education, 75(9), 188. https://doi.org/10.5688/ajpe759188

Croft, H., Gilligan, C., Rasiah, R., Levett-Jones, T., \& Schneider, J. (2019). Current trends and opportunities for competency assessment in pharmacy education-a literature review. Pharmacy, 7(2), 67.

https://doi.org/10.3390/pharmacy7020067

de Freitas, S., \& Oliver, M. (2006). How can exploratory learning with games and simulations within the curriculum be most effectively evaluated? Computers \& Education, 46(3), 249-264

Deci, E. L., \& Ryan, R. M. (2008). Self-determination theory: A macrotheory of human motivation, development, and health. Canadian Psychology, 49(3), 182-185. https://doi.org/10.1037/a0012801

Electronic Arts Inc. (2020). EA Games: SimCity ${ }^{\mathrm{TM}}$. Available at: https://www.ea.com/games/simcity

Englund, C., \& Sjöström, H.-E. (2011). Communication training in a virtual pharmacy. In Reformation, Revolution, Evolution (pp. 11)
Fens, T., Dantuma-Wering, C. M., \& Taxis, K. (2020). The Pharmacy Game-GIMMICS ${ }^{\circledR}$ a Simulation Game for Competency-Based Education. Pharmacy, 8(4), 198. https://doi.org/10.3390/pharmacy8040198

Fens, T., Hope, D. L., Crawshaw, S., Tommelein, E., Dantuma-Wering, C., Verdel, B. M., Trečiokienè, I., Solanki, V., van Puijenbroek, E. P., \& Taxis, K. (2021). The international Pharmacy Game: a comparison of implementation in seven universities world-wide. Pharmacy, 9(125). https://doi.org/10.3390/pharmacy9030125

Fernandez, R., Parker, D., Kalus, J. S., Miller, D., \& Compton, S. (2007). Using a Human Patient Simulation Mannequin to Teach Interdisciplinary Team Skills to Pharmacy Students. American Journal of Pharmaceutical Education, 71(3), 51. https://doi.org/10.5688/aj710351

Gaba, D. M. (2004). The future vision of simulation in health care. Quality and Safety in Health Care, 13(suppl 1), i2-i10. https://doi.org/10.1136/qshc.2004.009878

Gleason, B. L., Peeters, M. J., Resman-Targoff, B. H., Karr, S. McBane, S., Kelley, K., Thomas, T., \& Denetclaw, T. H. (2011). An active-learning strategies primer for achieving ability-based educational outcomes. American Journal of Pharmaceutical Education 75(9)

Harden, R. M. (1999). What is a spiral curriculum? Medical Teacher, 21(2), 141-143.

https://doi.org/10.1080/01421599979752

Harrow, A. J. (1972). A Taxonomy of the Psychomotor Domain: A Guide for Developing Behavioral Objectives: D. McKay

Hirsch, A. C., \& Parihar, H. S. (2014). A capstone course with a comprehensive and integrated review of the pharmacy curriculum and student assessment as a preparation for advanced pharmacy practice experiences. American Journal of Pharmaceutical Education, 78(10), Article 192. https://doi.org/10.5688/ajpe7810192

Hope, D. L., Rogers, G. D., Grant, G. D., \& King, M. A. (2021). Experiential learning in a gamified pharmacy simulation: a qualitative exploration guided by semantic analysis. Pharmacy, 9(81).

https://doi.org/10.3390/pharmacy9020081

Huang, H.-M., Rauch, U., \& Liaw, S.-S. (2010). Investigating learners' attitudes toward virtual reality learning environments: Based on a constructivist approach. Computers \& Education, 55(3), 1171-1182

Hussainy, S. Y., Styles, K., \& Duncan, G. (2012). A Virtual Practice Environment to Develop Communication Skills in Pharmacy Students. American journal of pharmaceutical education, 76(10)

Johnson, D. W., Johnson, R. T., \& Smith, K. (2007). The state of cooperative learning in postsecondary and professional settings. Educational Psychology Review, 19(1), 15-29

Kaplonyi, J., Bowles, K. A., Nestel, D., Kiegaldie, D., Maloney, S., Haines, T., \& Williams, C. (2017). Understanding the impact of simulated patients on health care learners' communication skills: a systematic review. Medical Education, 51(12), 1209-1219 
Kapp, K. M. (2012). The Gamification of Learning and Instruction: Game-based Methods and Strategies for Training and Education: Wiley

Kim, B. (2015). Understanding Gamification. 51(2). Chicago: American Library Association

Koster, A., Schalekamp, T., \& Meijerman, I. (2017). Implementation of competency-based pharmacy education (CBPE). Pharmacy, 5(1), 10.

https://doi.org/10.3390/pharmacy5010010

Krathwohl, D. R., Bloom, B. S., \& Masia, B. B. (1964). Taxonomy of Educational Objectives, Handbook II: The affective domain. New York: David McKay Company. New York: David McKay Co., Inc

Kubota, R., Shibuya, K., Tanaka, Y., Aoki, M., Shiomi, M., Ando, W., Otori, K., \& Komiyama, T. (2018). Clinical Pharmacy Education in Japan: Using Simulated Patients in Laboratory-Based Communication-Skills Training before Clinical Practice. Pharmacy, 6(2), 49

Lin, K., Travlos, D. V., Wadelin, J. W., \& Vlasses, P. H. (2011). Simulation and Introductory Pharmacy Practice Experiences. American Journal of Pharmaceutical Education, 75(10), 209. https://doi.org/10.5688/ajpe7510209

Lok, B., Ferdig, R. E., Raij, A., Johnsen, K., Dickerson, R., Coutts, J., Stevens, A., \& Lind, D. S. (2006). Applying virtual reality in medical communication education: current findings and potential teaching and learning benefits of immersive virtual patients. Virtual Reality, 10(3-4), 185-195

Lyons, J. (2012). Learning with technology: theoretical foundations underpinning simulations in higher education. Paper presented at the ascilite Conference

Mardjan, N. P. (2016). Serious gaming for systemic entrepreneurialism. 2nd and 3rd Regional Innovation and Entrepreneurship Conference

Marken, P. A., Zimmerman, C., Kennedy, C., Schremmer, R., \& Smith, K. V. (2010). Human Simulators and Standardized Patients to Teach Difficult Conversations to Interprofessional Health Care Teams. American Journal of Pharmaceutical Education, 74(7), 120.

https://doi.org/10.5688/aj7407120

McDougall, A. (2017). When I say... gamification. Medical Education

McGaghie, W. C., Issenberg, S. B., Petrusa, E. R., \& Scalese, R. J. (2010). A critical review of simulation-based medical education research: 2003-2009. Medical Education, 44(1), 50-63. https://doi.org/10.1111/j.1365-2923.2009.03547.x

Moncada, S. M., \& Moncada, T. P. (2014). Gamification of Learning in Accounting Education. Journal of Higher Education Theory \& Practice, 14(3)

Mottner, S. (2009). Experimenting with team norms in a marketing simulation. Journal for Advancement of Marketing Education, 15, 1-13

Mylrea, M. F., Sen Gupta, T., \& Glass, B. D. (2017). Developing professional identity in undergraduate pharmacy students: a role for self-determination theory.
Pharmacy, 5(2), 16.

https://doi.org/10.3390/pharmacy5020016

Nash, R. E., Chalmers, L., Brown, N., Jackson, S., \& Peterson, G. (2015). An international review of the use of competency standards in undergraduate pharmacy education. Pharmacy Education, 15

Okuda, Y., \& Quinones, J. (2008). The use of simulation in the education of emergency care providers for cardiac emergencies. International Journal of Emergency Medicine, 1(2), 73-77. https://doi.org/10.1007/s12245-008-0034-2

Orsini, C., Evans, P., \& Jerez, O. (2015). How to encourage intrinsic motivation in the clinical teaching environment?: a systematic review from the self-determination theory. Journal of Educational Evaluation for Health Professions, 12. https://doi.org/10.3352/jeehp.2015.12.8

Oxford Reference. (2019). World-Building Definition. Available at:

https://www.oxfordreference.com/view/10.1093/acref/978 0195305678.001.0001/acref-9780195305678-e-868

Paravattil, B., Kheir, N., \& Yousif, A. (2017). Utilization of simulated patients to assess diabetes and asthma counseling practices among community pharmacists in Qatar. International Journal of Clinical Pharmacy, 39(4), 759768

Pharmaceutical Society of Australia. (2016). National Competency Standards Framework for Pharmacists in Australia. Available at: https://www.psa.org.au/wpcontent/uploads/2018/06/National-Competency-StandardsFramework-for-Pharmacists-in-Australia-2016-PDF-2mb.pdf

Pharmaceutical Society of Australia. (2017). Professional Practice Standards - Version 5. Retrieved from https://my.psa.org.au/s/article/Professional-PracticeStandards

Phillips, B. B., Newsome, A. S., Bland, C. M., Palmer, R., Smith, K., DeRemer, D. L., \& Phan, S. V. (2019). Pharmacy Student Performance in a Capstone Course Utilizing the Pharmacists' Patient Care Process. American Journal of Pharmaceutical Education, 83(8), Article 7357. https://doi.org/10.5688/ajpe7357

Prensky, M. (2001). Fun, play and games: What makes games engaging. In Digital Game-Based Learning (pp. 1-31). California: McGraw-Hill

Reeve, J. (2002). Self-determination theory applied to educational settings. Handbook of self-determination research, 2, 183-204

Rogers, G. D., McConnell, H. W., De Rooy, N. J., Ellem, F., \& Lombard, M. (2014). A randomised controlled trial of extended immersion in multi-method continuing simulation to prepare senior medical students for practice as junior doctors. BMC Medical Education, 14, 90. https://doi.org/10.1186/1472-6920-14-90

Rogers, G. D., Mey, A., \& Chan, P. C. (2017). Development of a phenomenologically derived method to assess affective learning in student journals following impactive educational experiences. Medical Teacher, 39(12), 1250-1260. https://doi.org/10.1080/0142159X.2017.1372566 
Rogers, G. D., Mey, A., Chan, P. C., Lombard, M., \& Miller, F. (2018). Development and validation of the Griffith University Affective Learning Scale (GUALS): A tool for assessing affective learning in health professional students' reflective journals. MedEdPublish, 1-8.

https://doi.org/10.15694/mep.2018.000002.1

Ryall, T., Judd, B. K., \& Gordon, C. J. (2016). Simulationbased assessments in health professional education: a systematic review. Journal of Multidisciplinary Healthcare, 9, 69

Sauvé, L., Renaud, L., Kaufman, D., \& Marquis, J.-S. (2007). Distinguishing between Games and Simulations: A Systematic Review. Educational Technology \& Society, 10(3), 247-256

Schaafsma, E., Dantuma-Wering, C., Van Wieren, D., Sarre, S., \& De Paepe, K. (2010). A Pharmacy Game: Experiencing the Possibilities of an Active and Reflective Learning Style. Paper presented at the 16th International Social Pharmacy Workshop: Communication and Information in Pharmacy Lisbon, 23-26 August

Schoenly, L. (1994). Teaching in the affective domain. Journal of Continuing Education in Nursing, 25(5), 209-212. https://doi.org/10.3928/0022-0124-19940901-06

Schwabe, G., \& Göth, C. (2005). Mobile learning with a mobile game: design and motivational effects. Journal of Computer Assisted Learning, 21(3), 204-216. https://doi.org/10.1111/j.1365-2729.2005.00128.x

Shreve, J. (2005). Let the Games Begin. Video Games, Once Confiscated in Class, Are Now a Key Teaching Tool. If They're Done Right. George Lucas Educational Foundation

Sillius, A., \& Van Der Werf, J. J. (2005). GIMMICS: How to organize, manage and control a pharmacy practice game. $E$ Learning: Design, Development and Delivery

Smithson, J., Bellingan, M., Glass, B., \& Mills, J. (2015). Standardized patients in pharmacy education: An integrative literature review. Currents in Pharmacy Teaching and Learning, $7(6), 851-863$

Social Research Centre Pty Ltd, \& Commonwealth of Australia. (2020). QILT Quality Indicators of Learning and Teaching. Available at: https://www.qilt.edu.au/

Thomas, D. R. (2006). A general inductive approach for analyzing qualitative evaluation data. American Journal of Evaluation, 27(2), 237-246. https://doi.org/10.1177/1098214005283748

Van Der Werf, J. J., Dekens-Konter, J., \& Brouwers, J. R. (2004). A new model for teaching pharmaceutical care services management. Pharmacy Education, 4(3-4), 165169. https://doi.org/10.1080/15602210400013368

Virvou, M., Katsionis, G., \& Manos, K. (2005). Combining Software Games with Education: Evaluation of its Educational Effectiveness. Educational Technology \& Society, 8(2), 54-65

Vyas, D., McCulloh, R., Dyer, C., Gregory, G., \& Higbee, D. (2012). An Interprofessional Course Using Human Patient Simulation to Teach Patient Safety and Teamwork Skills.
American Journal of Pharmaceutical Education, 76(4), 71. https://doi.org/10.5688/ajpe76471

Whelan, D. L. (2005). Let the games begin. School Library Journal, 51(4), 40-43

Whitton, N., \& Hollins, P. (2008). Collaborative virtual gaming worlds in higher education. Research in Learning Technology, 16(3)

Wiggins, G., \& McTighe, J. (2005). Understanding by Design: ASCD

Williams, G. C., Saizow, R. B., \& Ryan, R. M. (1999). The importance of self-determination theory for medical education. Academic Medicine 